\title{
Dendritic Cells in Autoimmune Diseases
}

\author{
Mohan S. Maddur ${ }^{1,2,3}$, Janakiraman Vani ${ }^{1,2,3}$, Jordan D. Dimitrov ${ }^{1,2,3}$, Kithiganahalli N. Balaji ${ }^{4}$, \\ Sébastien Lacroix-Desmazes ${ }^{1,2,3}$, Srini V. Kaveri ${ }^{1,2,3}$ and Jagadeesh Bayry*,1,2,3
}

\author{
${ }^{1}$ Institut National de la Santé et de la Recherche Médicale, Unité 872, 15 rue de l’Ecole de Médicine, Paris, F-75006, \\ France \\ ${ }^{2}$ Centre de Recherche des Cordeliers, Equipe 16- Immunopathology and Therapeutic Immunointervention, Université \\ Pierre et Marie Curie - Paris 6, UMR S 872, 15 rue de l'Ecole de médicine, Paris, F-75006, France \\ ${ }^{3}$ Université Paris Descartes, UMR S 872, 15 rue de l'Ecole de médicine, Paris, F-75006, France \\ ${ }^{4}$ Department of Microbiology and Cell Biology, Indian Institute of Science, Bangalore 560012, India
}

\begin{abstract}
Dendritic cells (DCs) are professional antigen presenting cells, which play a crucial role both in maintaining immune tolerance and in inducing adaptive immune responses. Therefore, DCs are the most sought in inciting autoimmunity and its sustenance to autoimmune diseases. The emerging knowledge of the importance of DCs, DC-derived cytokines, and intracellular signal transduction pathways in mediating autoimmune diseases and in creating an inflammatory environment provides a rationale for pursuing strategies to block these inflammatory pathways for therapeutic purposes.
\end{abstract}

Keywords: Dendritic cells, Autoimmunity, Rheumatology, Rheumatoid Arthritis, Lupus, Kawasaki disease, T cells, cytokines, co-stimulation.

Dendritic cells (DCs) are the prototype professional antigen presenting cells (APCs) derived from hemopoietic cells and are essential link between innate and adaptive arms of the immune system. They are sparse, but widely distributed in different types of tissues, serving as sentinels of the immune system [1]. DCs are capable of stimulating naïve $T$ lymphocytes and hence play a central role in initiating primary immune responses [2]. In addition, DCs also play a critical role in maintaining immune tolerance through cross talk with $\mathrm{T}$ and $\mathrm{B}$ cells $[1,3]$.

\section{SUBSETS OF DENDRITIC CELLS}

Despite similar basic function of antigen presentation, DCs differ in their developmental pathways, location, migratory properties, phenotypic markers and immunological functions. Thus, DCs are heterogeneous and several subtypes with distinct features have been identified in lymphoid and non-lymphoid tissues of human and mouse [1,3]. The major subtypes of human DCs are Langerhans cells, interstitial dermal DCs, monocyte-derived inflammatory DCs (MoDCs), BDCA $-1^{+}$and BDCA- $3^{+}$myeloid DC subsets, and plasmacytoid DCs (pDCs). The major subsets of mouse DCs include $\mathrm{CD} 4 \mathrm{CD} 8 \alpha^{\mathrm{hi}} \mathrm{CD} 205^{\mathrm{hi}} \mathrm{CD} 11 \mathrm{~b}^{-}$DCs, $\mathrm{CD} 4^{+} \mathrm{CD} 8 \alpha^{-}$ CD $205^{-} \mathrm{CD} 11 \mathrm{~b}^{+} \mathrm{DCs}, \mathrm{CD} 4{ }^{-\mathrm{CD}} 8 \alpha^{-} \mathrm{CD} 205^{-} \mathrm{CD} 11 \mathrm{~b}^{+} \mathrm{DCs}, \mathrm{CD}^{-}$ $\mathrm{CD} 8 \alpha^{-} \mathrm{CD} 205^{+} \mathrm{CD} 11 \mathrm{~b}^{-}$DCs, plasmacytoid DCs, and Langerhans DCs [3]. However, as depicted in Table 1, human and mouse DC subsets vary in their expression of CD markers (Table 1) [4].

\footnotetext{
*Address correspondence to this author at the INSERM U 872, Equipe 16, Centre de Recherche des Cordeliers, 15 rue de l'Ecole de Médicine, Paris, F-75006, France; Tel: 00331554282 66; Fax: 00331554282 62; E-mail: jagadeesh.bayry@crc.jussieu.fr
}

\section{MATURATION AND ACTIVATION OF DENDRITIC CELLS}

Phenotypically, DCs are identified in "immature" and "mature" stage, based on the expression of surface markers [2]. Resting or immature DCs have high capacity to capture and internalize antigens due to surface expression of receptors that enables the recognition and endocytosis of potential antigens. These receptors include members of pattern recognition receptors (PRRs) family (such as Toll-like receptors (TLRs), C-type lectin receptors (CLRs), intracytoplasmic nucleotide oligomerization domain (NOD)-like receptors (NLRs)), Fc receptors (FcR), complement receptors, scavenger receptors and receptors involved in uptake of apoptotic bodies such as phosphatidylserine receptor. The expression of surface receptors differs with DC subsets and hence enables identification of subtypes [4]. DCs also possess numerous cytokine receptors that enable them to respond to the appropriate stimuli. Thus, immature DCs act as immunological sensors that receive stimuli from environment to alert the immune system. However, immature DCs are poor stimulators of $\mathrm{T}$ cells and must undergo a maturation and activation process.

Upon antigen capture by immature DCs, a complex process of maturation and activation is initiated based on the nature of the stimuli. The molecules that provide maturationassociated signals include pathogen-derived molecules (eg., dsRNA, LPS, CpG), dying cell components, tissue factors such as hyaluronan fragments, heparin sulphate, immune complexes and inflammatory cytokines [5]. The components of the dying cells include heat shock proteins (HSPs), highmobility group box 1 proteins (HMGB1), $\beta$-defensins, ATP and uric acid, which are collectively called damageassociated molecular pattern molecules (DAMPS) [6]. NF- 
Table 1. Differentiation Markers on Different Subsets of DCs in Human and Mice

\begin{tabular}{|c|c|c|c|c|}
\hline $\begin{array}{l}\text { Human DC } \\
\text { Subsets }\end{array}$ & $\begin{array}{l}\text { Epidermal Langerhans } \\
\text { Cells }\end{array}$ & Dermal Interstitial DCs & Blood Myeloid DCs & $\begin{array}{l}\text { Blood Plasmacytoid } \\
\text { DCs }\end{array}$ \\
\hline C-type lectins & Langerins & DC-SIGN, Mannose receptor & $\begin{array}{l}\text { DC-SIGN, Mannose } \\
\text { receptor }\end{array}$ & BDCA-2 \\
\hline $\begin{array}{l}\text { Specific } \\
\text { Molecules }\end{array}$ & CD11c, CD1a, E-cadherin & $\begin{array}{c}\text { CD11c, CD1a/CD14, CD11b, CD36, } \\
\text { FactorXIIIa }\end{array}$ & $\mathrm{CD} 11 \mathrm{c}$ & CD123, ILT7 \\
\hline
\end{tabular}

\begin{tabular}{|c|c|c|c|c|c|c|}
\hline $\begin{array}{l}\text { Mouse DC } \\
\text { subsets }\end{array}$ & $\mathrm{CD} \alpha^{+} \mathrm{CD}^{-}$ & $\mathrm{CD} 8 \alpha^{-\mathrm{CD}^{-}}$ & $\mathrm{CD}^{-\mathrm{CD}^{+}}{ }^{+}$ & $\begin{array}{c}\mathrm{CD8} \alpha \\
\mathrm{CD4}\end{array}$ & $\begin{array}{l}\text { 'Langerhans' DCs } \\
\text { CD8 } \alpha^{\text {low }} \text { CD4 }\end{array}$ & Plasmacytoid DCs \\
\hline C-type lectins & DEC205 $5^{\text {high }}$ & DEC205- & DCIR & DEC $205^{+}$ & DEC205 $5^{\text {high }}$, Langerin & DEC205- \\
\hline $\begin{array}{c}\text { Specific } \\
\text { Molecules }\end{array}$ & $\begin{array}{c}\text { CD8, } \\
\text { CD11 } c^{\text {high }}\end{array}$ & $\begin{array}{l}\text { CD11b, } \\
\text { CD11 } c^{\text {high }}\end{array}$ & $\begin{array}{l}\mathrm{CD} 4, \mathrm{CD} 11 \mathrm{~b}, \\
\mathrm{CD} 11 \mathrm{c}^{\text {high }}\end{array}$ & CD11 $\mathrm{c}^{\text {high }}$ & $\mathrm{CD} 11 \mathrm{~b}$ & $\begin{array}{c}\mathrm{CD} 11 \mathrm{c}^{\text {low }}, \mathrm{CD} 4^{\text {low }}, \mathrm{B} 220 \\
(\mathrm{CD} 45 \mathrm{R})\end{array}$ \\
\hline
\end{tabular}

DCIR= Dendritic cell immunoreceptor. Markers that are useful for segregating mouse DC subtypes include CD11b and the interdigitating DC marker CD205 (the multilectin domain moleculeDEC205, originally known as NLDC-145). The upper table is reproduced from Immunol Rev 2007; 219: 118-142 (ref. [4]) with permission from Wiley-Blackwell.

$\kappa \mathrm{B}$ and mitogen-activated protein kinase are the two major signaling pathways that are activated by these stimuli during maturation of DCs [7,8].

Maturation is defined as the series of phenotypic changes that enables DCs to initiate immunity as professional APCs [9]. This process involves similar morphological and functional changes in both human and mouse DCs [9] that include (i) loss of endocytic/phagocytic receptors; (ii) morphological changes such as the loss of adhesive structures, cytoskeleton reorganization, and the acquisition of high cellular motility; (iii) secretion of immunoregulatory cytokines and chemokines such as IL-1 $\beta$, IL-6, IL-10, IL-12, IL-23, TNF, CCL17, CCL19 and CCL22; (iv) up-regulation of costimulatory and adhesion molecules CD80, CD86, CD40, CD54, CD58 critical in mediating clustering with and activation of T cells; (v) translocation of MHC class I/II compartments to the cell surface; and (vi) migration of mature DCs into regional/draining lymphoid tissue. As a result, antigen acquired in peripheral sites is retained, processed and presented to $\mathrm{T}$ cells in lymph nodes.

\section{INDUCTION OF ADAPTIVE IMMUNE RESPONSES BY DENDRITIC CELLS}

The process of T-cell activation is regulated primarily by signaling events derived from the T-cell receptor TCR (signal 1) and from co-stimulatory and adhesion molecules (signal 2) CD80, CD86, CD40, CD54, CD58 on APCs and CD28, CD154, CD11a and CD2 on T cells. The CD80 and/or CD86-CD28 interactions provide signals important for T-cell activation and survival. CD40-CD154 interactions are crucial for the development of $\mathrm{CD}^{+}{ }^{+} \mathrm{T}$-dependent effector functions such as help for B-cell differentiation and class switch. The interactions of adhesion molecules CD54 and CD11a, and CD58 and CD2 play a central part in the clustering of DCs and $\mathrm{CD}^{+} \mathrm{T}$ lymphocytes and facilitate TCR triggering by increasing T-cell-DC interactions at low antigen densities. An additional signal has also been proposed in the form of immunomodulatory cytokines (signal 3) produced by activated DCs that dictate the polarization of $\mathrm{CD}^{+}$ T cells towards Th1, Th2, Th17 or regulatory T cells (Tregs) (Fig. 1) [10]. Interleukin (IL)-12 has an important role in the differentiation of Th1 cells, and IL-4 is crucial for Th2 dif- ferentiation. IL-1 $\beta$ and IL-6 promote IL-17 and IL-21 production from activated and memory human T cells. IL-21 promotes the differentiation of human Th17 cells from naïve CD4+ $\mathrm{T}$ cells in the presence of transforming growth factor (TGF)- $\beta$, whereas IL-23 might further expand or stabilize differentiated Th17 cells [11-14].

In addition to $\mathrm{T}$ cell stimulation, DCs contribute to the stimulation of $\mathrm{B}$ cells, both in the lymph node $\mathrm{T}$ cell areas and in germinal centers. Antigens in the immune complex captured by inhibitory $\mathrm{Fc}$ receptor (FcR $\gamma \mathrm{IIB})$ can be retained in non-degradative intracellular vesicles and presented in native form to B cells [15]. DCs can also modulate the functions of non-specific effectors such as natural killer cells and natural killer $\mathrm{T}$ cells and influence the outcome of immune response $[16,17]$.

\section{DENDRITIC CELLS IN IMMUNE TOLERANCE: GENERATION OF REGULATORY T CELLS}

In addition to their central role in initiating adaptive immunity, DCs are also involved in the induction of immune tolerance in both central and peripheral compartments by different regulatory mechanisms that include, clonal deletion, clonal anergy, receptor editing of T/B cells and generation of Tregs $[16,17]$. Role of DCs in generation of regulatory $\mathrm{T}$ cells is of prime importance [15]. In human thymus, the thymic stromal lymhopoietin (TSLP) derived from the hassall's corpuscles instruct DCs to switch from negative selection of autoreactive $\mathrm{T}$ cells to positive selection of natural Tregs (nTregs). Interestingly, the preformed immature myeloid tolerogenic DCs carrying peripheral antigens migrate into the thymus and induce the generation of nTregs in vivo [15]. In addition, immature/tolerogenic DCs or DCs stimulated to produce IL-10/ TGF- $\beta$ induce Tregs in peripheral tissues referred to as induced regulatory cells (iTregs) $[18,19]$. Tregs play a crucial role in maintaining immune tolerance by acting on several cellular targets [20,21].

\section{DENDRITIC CELLS: INCITING AND SUSTAINING AUTOIMMUNITY}

Autoimmunity refers to inappropriate immune response against self-components of the host that might result in 
a
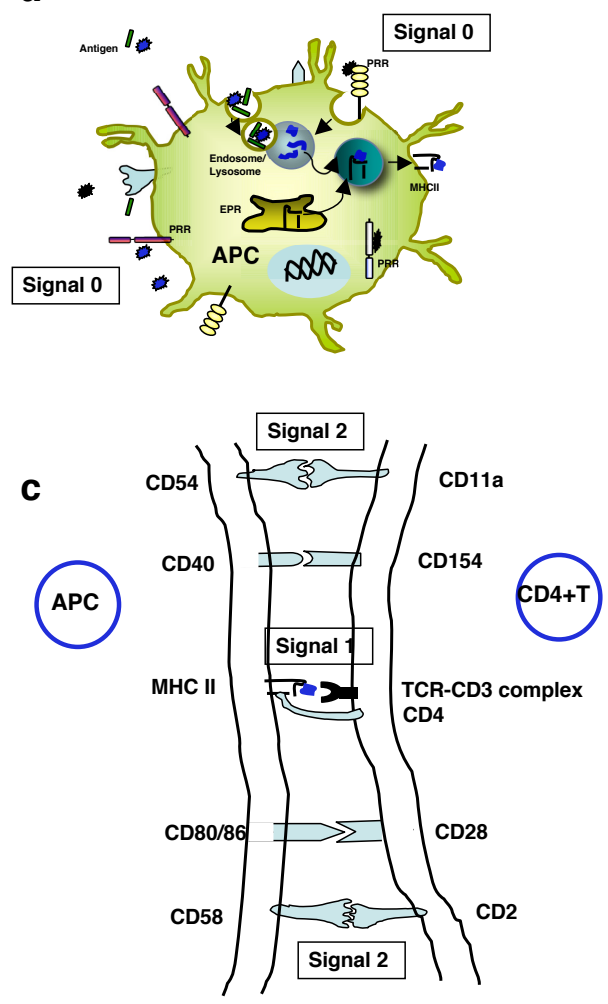
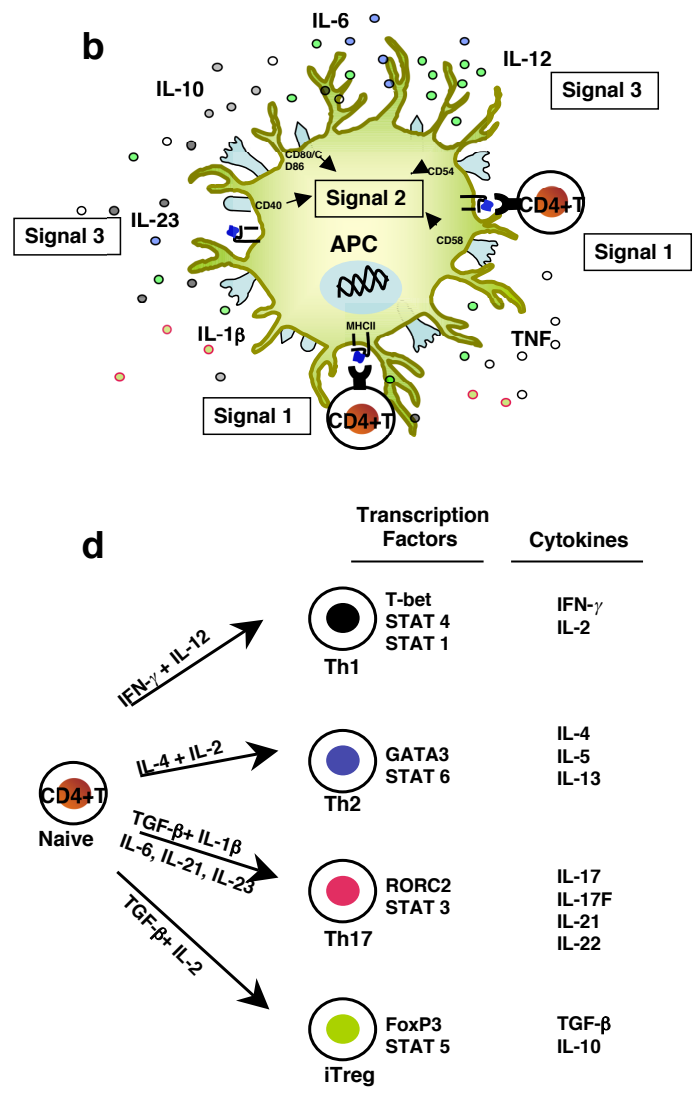

Fig. (1). Stimulation and differentiation of $\mathrm{CD} 4+\mathrm{T}$ cells by dendritic cells.

(a) Immature DCs present with high capacity to take up exogenous antigens. The recognition of antigen-associated PAMPs by PRRs (signal 0) leads to maturation and activation of DCs. In endosomes/lysosmes, the internalized antigens are processed into smaller peptides. These antigenic peptides bind to MHC II molecules and transported to cell surface. EPR, endoplasmic reticulum (b) The 'antigen-educated' DCs present antigenic peptides in the context of MHC II to TCR of naïve CD4+T cells (Signal 1). These mature and activated DCs express high levels of MHC, co-stimulatory (CD40, CD80 and CD86) and adhesion molecules (CD54 and CD58) (signal 2) and secrete high amounts of cytokines IL-1 $\beta$, IL-6, IL-10, IL-12, IL-23 and TNF (Signal 3) that play a critical role in inflammation and differentiation of CD4+T cells. (c) The interaction of signaling molecules at APC-T cell interface (d) CD4+T cells under the influence of signaling by DCs and DC-derived cytokines can be differentiated into 4 distinct subclasses expressing distinct transcription factors: Th1, Th2, Th17 and induced Tregs (iTregs). The figure is reprinted from Trends Pharmacol Sci 2009, 30:287-295 (ref. [10]) with permission from Elsevier.

pathological conditions. A low level of autoreactivity is acknowledged as physiologic and crucial for normal immune function [22]. Autoimmune diseases are clinical syndromes that occur in selected genetic backgrounds characterised by the abnormal activation of $\mathrm{T}$ cells, $\mathrm{B}$ cells or both in the $\mathrm{ab}-$ sence of on going infection or other discernible cause [23]. Autoimmune diseases affect approximately 5\% of the population based on genetic characters and environmental factors. They can be clinically classified either systemic (eg., systemic lupus erythematosus (SLE) or organ specific (eg., type 1 diabetes mellitus) [23].

A breakdown in immune tolerance is central to the initiation and progression of an autoimmune disease. Given the central role in induction of immune response and tolerance, DCs are the most sought after cells in inciting autoimmunity and its sustenance to autoimmune diseases [18, 24-28]. In human leukocyte antigen-restricted autoimmune diseases, DC priming of the immune response in lymphoid organs is a requisite first step that leads to the activation of $\mathrm{T}$ cells and the production of pathogenic autoantibodies and the ensuing chronic inflammatory process [29-31]. Individuals with autoimmune disease show a high number of aberrantly activated DCs either in circulation or in the autoimmune lesions secreting large amounts of proinflammatory cytokines that mediate inflammation and differentiation of pathogenic Th1 and Th17 cells [26]. In the mouse model, altered DC homeostasis has been demonstrated to result in an apparent autoimmune response, thus signifying a central role of DCs in maintaining immune self-tolerance and potential to incite autoimmunity $[32,33]$. Further, defects in the apoptosis of the immune cells and defective clearance of apoptotic cell debris due to an impaired uptake can result in development of autoimmunity. The priming of autoreactive lymphocytes by activated DCs that have taken up apoptotic materials may lead to break down of self-tolerance [34]. The role of TLRs expressed on different DC subsets has been increasingly evidenced in the pathogenesis of many autoimmune diseases $[35,36]$. An important sequel of continued antigenic stimula- 
tion via DCs is the formation of lymphoid structures at the site of inflammation. By coordinating the recruitment and/or activation of other immune cells, DCs can drive the generation of ectopic lymphoid tissues, as in the case of inflamed synovia in rheumatoid arthritis (RA) and SLE [18, 19].

Although Tregs can suppress the maturation and activation and the production of inflammatory cytokines by recently activated DCs (Fig. 2) [31, 37-40], chronically activated DCs can escape suppression by Tregs and generate activated $\mathrm{T}$ cells that are refractory to the suppression by Tregs. High amounts of pro-inflammatory cytokines that are released by DCs due to constant and prolonged activation can render Tregs functionally defective. For example, prolonged exposure to TNF can inhibit the expression of FoxP3 and the function of Tregs by signaling through TNF receptor II [41]. Further, IL-6, IL-12, and IL-1 $\beta$ may also promote autoimmunity by interfering with the regulatory functions of Tregs and promoting activation and expansion of effector $\mathrm{T}$ cells [31]. In addition to directly suppressing the functions of Tregs, DC-derived cytokines such as IL-6, IL-1 $\beta$, and IL-23 can reciprocally regulate the populations of iTregs and IL17-producing pathogenic Th17 cells [42].

Type 1 interferons (IFN- $\alpha$ and IFN- $\beta$ ) are secreted in large amount by pDCs not only following viral infection, but also in autoimmune diseases [1]. In psoriasis, pDCs accumulate in the inflamed skin at an early stage of the disease, and these cells secrete type I IFN [43]. In insulin-dependent diabetes mellitus, elevated expression of IFN was found in the pancreas of recently diagnosed patients, though the role of pDCs is unclear [44]. In idiopathic inflammatory myopathies, DCs present in inclusion body myositis and polymyositis are primarily myeloid DCs, whereas in dermato-
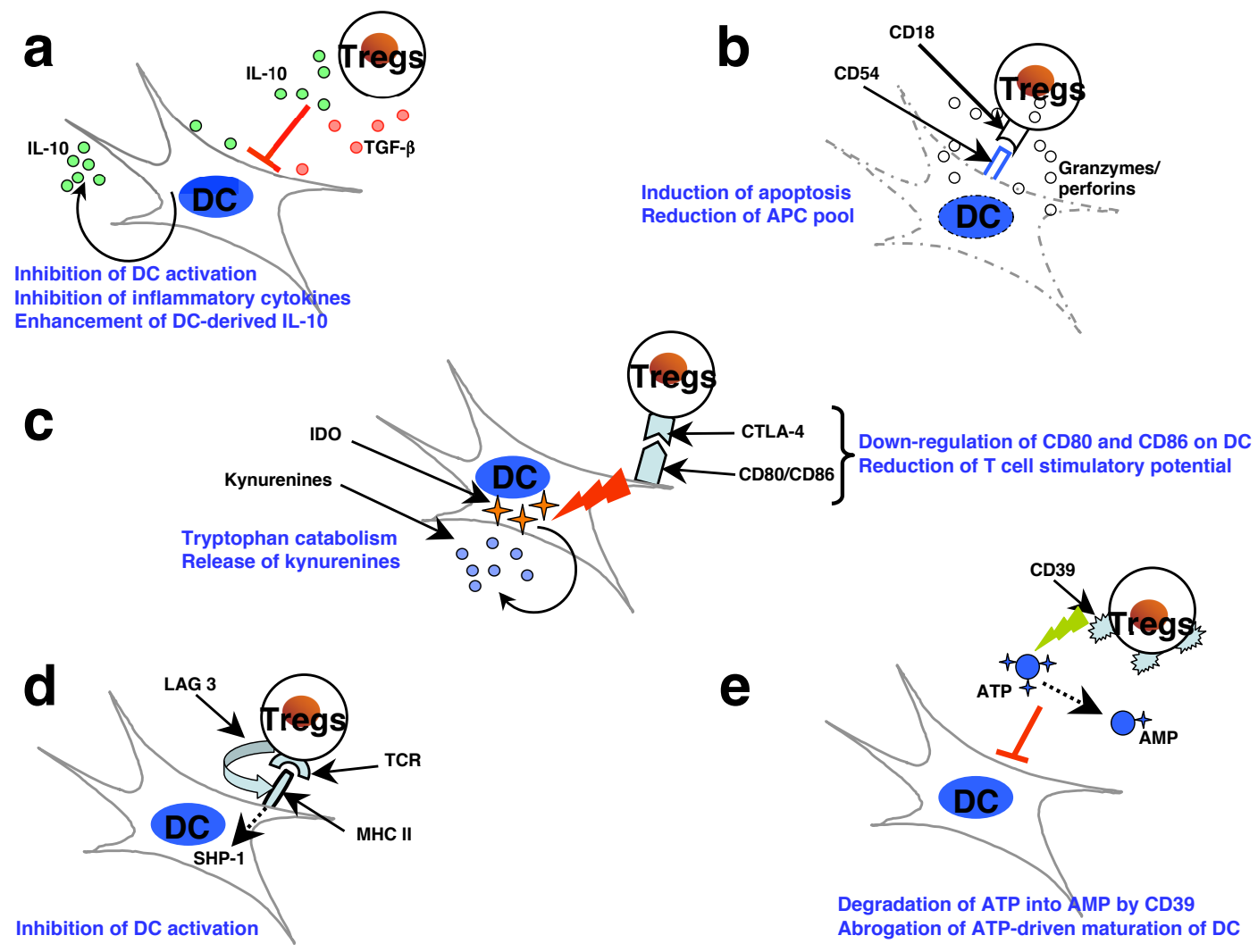

Fig. (2). The mechanisms of suppression of dendritic cells by Tregs.

Several mutually nonexclusive mechanisms have been proposed to account for the modulation of DCs by Tregs. The suppression of DCs by Tregs is mediated by both soluble factors and cell-associated molecules. However, recent reports suggest that CTLA-4 molecule has a key role in Treg-mediated suppressive functions. (a) Treg-derived IL-10 and TGF- $\beta$ induce a suppressive phenotype in DCs and inhibit inflammatory cytokine expression by DCs while enhancing the secretion of the anti-inflammatory cytokine IL-10. (b) Activated Tregs express high levels of granzyme A and perforin and exert CD18/CD54 adhesive interaction-dependent cytotoxicity against both immature and mature DCs, thus reducing the antigen-presenting and co-stimulatory pool. (c) CTLA-4 interaction with B7 molecules transduces a negative signal for DCs CTLA-4 diminishes the co-stimulatory molecules CD80 and CD86 and converts DCs into less potent APCs with reduced T cell stimulatory potential. CTLA-4 can also induce indoleamine 2,3-dioxygenase (IDO) expression in DCs. IDO catalyzes the conversion of tryptophan into kynurenines, which are potent immunosuppressive metabolites. (d) Tregs can interact with MHC class II on DCs via lymphocyte activation gene-3 (LAG-3), a CD4-related transmembrane protein that inhibits DC activation by a mechanism involving ERK-mediated recruitment of SHP-1. (e) Tregs express CD39 (nucleoside triphosphate diphosphohydrolase-1), an ectoenzyme that degrades ATP to AMP. Thus, Tregs reduce ATP-mediated activation of DCs and the adjuvant activities of ATP. Some of these mechanisms are also reported to be critical in Treg-mediated regulation of functions of macrophages and B cells. The figure is reprinted from Am J Pathol 2009, 174:1575-1587 (Ref. [31]) with permission from the American Society for Investigative Pathology. 
myositis, type I IFN producing pDCs have been found abundantly in muscle tissue [45]. In Sjogren's syndrome, an autoimmune disease affecting mainly salivary and lacrimal glands, pDCs infiltrate salivary glands, where IFN-inducible genes are over-expressed [46]. In immune thrombocytopenic pupura patients, DCs are found to be highly efficient in presenting apoptotic platelets and stimulating autologous T-cell proliferation [47].

\section{DENDRITIC CELLS IN AUTOIMMUNE DISEASES: FEW SPECIFIC EXAMPLES}

\section{Rheumatoid Arthritis (RA)}

Spontaneous arthritis animal models resembling RA have revealed defects related to interaction of DCs and thymocytes and as a consequence escape of pathogenic autoreactive $\mathrm{T}$ cells. These $\mathrm{T}$ cells upon stimulation by activated DCs in the presence of TNF- $\alpha$ and IL- 1 are shown to drive autoantibody production and proinflammatory arthritogenic response [48]. Further, DCs can present altered citrullinated collagens and fibrin to autoreactive T cells (Table 2) [49]. DCs enter the inflamed synovium through blood vessels and are found to have activated NF- $\kappa B$ pathway. Mature myeloid DCs are in perivascular $\mathrm{T}$ cell rich areas of synovial tissue and immature DCs are abundant in the synovial lining and sublining layers of synovium [28, 49]. Myeloid DCs can enhance inflammation in the synovium by secreting IL-23 that induces Th17 cells. pDCs are also observed in the inflamed synovium that might respond to immunostimulatory nucleic acid sequences complexed to rheumatoid factor, by producing IFN- $\alpha$ [50]. TNF- $\alpha$ is a dominant inflammatory cytokine that is over-produced in the joints by macrophages and mature myeloid DCs [51].

\section{Systemic Lupus Erythematosus (SLE)}

IFN- $\alpha$ is the cytokine implicated in pathogenesis of SLE. pDCs are the main source of IFN- $\alpha$, produced in response to nucleic acid-containing immune complexes which are de- tected by TLR7 and TLR9 (Table 2) [52]. Unabated induction of DC maturation by IFN- $\alpha$ has been proposed to drive the autoimmune responses in systemic SLE [53]. Thus, IFN$\alpha$ induces differentiation and activation of DCs from monocytes in SLE individuals, which can activate autoreactive T and $B$ cells [53, 54]. IFN- $\alpha / \beta$ also enhances B-cell response to nucleic acid-containing immune complexes by upregulating TLR7 and promoting cell death to release increased amounts of nucleic acid. pDC-produced IFNs initiate a selfperpetuating feedback loop to drive autoantibody production in SLE [52]. Aberrant phenotype and function of DCs in SLE is also observed [55-57].

\section{Multiple Sclerosis (MS)}

MS is a T cell-mediated disease, where Th1 and Th17 cells predominate resulting in chronic inflammation, demyelination and progressive paralysis [58]. DCs are recruited to MS lesions, where uptake and presentation of self-antigens which are made available by continuous myelin destruction, may contribute to the local activation and expansion of presumably pathogenic $\mathrm{T}$ cells (Table 2) [59,60]. DCs found within MS lesions have been shown to be functionally abnormal [61]. Further, intra-cerebral DCs were found to critically modulate encephalitogenic versus regulatory immune responses in CNS of EAE mice, an animal model of MS and hence considered to be rate-limiting factor for neuroinflammation [62].

\section{CONCLUSION}

DCs are the prime initiators and mediators of autoimmune diseases in an altered host microenvironment (cytokine imbalance) arising out of environmental and genetic perturbations. DCs act in concert with adaptive and other innate immune cells in moulding the autoimmune response. The emerging knowledge of the importance of DCs, DC-derived cytokines, and intracellular signal transduction pathways in mediating and creating an inflammatory environment in autoimmune diseases provides a rationale for pursuing

Table 2. The Role of DC Subsets in Human Autoimmune Diseases

\begin{tabular}{|l|l|}
\hline Disease & Role of Dendritic Cells \\
\hline \hline \multirow{2}{*}{ Rheumatoid arthritis } & $\begin{array}{l}\text { mDCs present citrullinated collagens and fibrin to autoreactive T cells and drive autoantibody and TNF-a pro- } \\
\text { duction }\end{array}$ \\
\cline { 2 - 3 } & pDCs produce IFN-a in response to nucleic acid sequences complexed to rheumatoid factor \\
\hline \multirow{2}{*}{ Systemic lupus erythematosus } & $\begin{array}{l}\text { pDCs produce IFN-a in response to nucleic acid-containing immune complexes which signal through TLR7 and } \\
\text { TLR9 }\end{array}$ \\
\cline { 2 - 3 } & pDC-produced IFNs drive autoantibody production \\
\hline \multirow{2}{*}{ Multiple Sclerosis } & mDCs present self-antigens of myelin to pathogenic T cells \\
\cline { 2 - 3 } & Intra-cerebral DCs modulate encephalitogenic versus regulatory immune responses in CNS \\
\hline Psoriasis & pDCs in inflammed skin secrete IFN-a \\
\hline Insulin-dependent diabetes mellitus & pDCs might be involved in IFN-a secretion in pancreas \\
\hline Myositis and Polymyositis & mDCs are mainly found at the site of lesions \\
\hline Dermatomyositis & Type I IFN producing pDCs are abundant \\
\hline Sjogren's syndrome & pDCs in salivary glands might favour IFN-inducible genes \\
\hline
\end{tabular}


strategies to block these inflammatory pathways for the therapeutic purposes.

\section{ACKNOWLEDGEMENTS}

Supported by grants Institut National de la Santé et de la Recherche Médicale (INSERM), Centre National de la Recherche Scientifique (CNRS), Université Paris DescartesParis 5, Université Pierre et Marie Curie-Paris 6, Agence Nationale de la Recherche (ANR-07-JCJC-0100-01), Coopération Institut National de la Santé et de la Recherche Médicale-Indian Council for Medical Research (INSERM-ICMRAO 2009/2010, eSPIN (European Scientific Progress - Immunoglobulins in Neurology) award 2009 and Talents research grant from Talecris Biotherapeutics.

\section{REFERENCES}

[1] Shortman K, Naik SH. Steady-state and inflammatory dendriticcell development. Nat Rev Immunol 2007; 7: 19-30.

[2] Banchereau J, Steinman RM. Dendritic cells and the control of immunity. Nature 1998; 392: 245-52.

[3] Shortman K, Liu YJ. Mouse and human dendritic cell subtypes. Nat Rev Immunol 2002; 2: 151-61.

[4] Ueno H, Klechevsky E, Morita R, et al. Dendritic cell subsets in health and disease. Immunol Rev 2007; 219: 118-42.

[5] Steinman RM, Turley S, Mellman I, Inaba K. The induction of tolerance by dendritic cells that have captured apoptotic cells. J Exp Med 2000; 191: 411-6.

[6] Seong SY, Matzinger P. Hydrophobicity: an ancient damageassociated molecular pattern that initiates innate immune responses. Nat Rev Immunol 2004; 4: 469-78.

[7] Ghosh S, May MJ, Kopp EB. NF-kappa B and Rel proteins: evolutionarily conserved mediators of immune responses. Annu Rev Immunol 1998; 16: 225-60.

[8] O'Sullivan B, Thompson A, Thomas R. NF-kappa B as a therapeutic target in autoimmune disease. Expert Opin Ther Targets 2007; 11: 111-22.

[9] Villadangos JA, Schnorrer P. Intrinsic and cooperative antigenpresenting functions of dendritic-cell subsets in vivo. Nat Rev Immunol 2007; 7: 543-55.

[10] Aimanianda V, Haensler J, Lacroix-Desmazes S, Kaveri SV, Bayry J. Novel cellular and molecular mechanisms of induction of immune responses by aluminum adjuvants. Trends Pharmacol Sci 2009; 30: 287-95.

[11] Sporri R, Reis e Sousa C. Inflammatory mediators are insufficient for full dendritic cell activation and promote expansion of CD4+ T cell populations lacking helper function. Nat Immunol 2005; 6: 163-70.

[12] Blander JM, Medzhitov R. Toll-dependent selection of microbial antigens for presentation by dendritic cells. Nature 2006; 440: 80812.

[13] van Kooyk Y, Geijtenbeek TB. Toll-like receptors keep antigen sorting on the right track. Immunity 2006; 25: 525-7.

[14] Zhu J, Paul WE. CD4 T cells: fates, functions, and faults. Blood 2008; 112: 1557-69.

[15] Bergtold A, Desai DD, Gavhane A, Clynes R. Cell surface recycling of internalized antigen permits dendritic cell priming of $\mathrm{B}$ cells. Immunity 2005; 23: 503-14.

[16] Kitamura H, Iwakabe K, Yahata $\mathrm{T}$, et al. The natural killer $\mathrm{T}$ (NKT) cell ligand alpha-galactosylceramide demonstrates its immunopotentiating effect by inducing interleukin (IL)-12 production by dendritic cells and IL-12 receptor expression on NKT cells. J Exp Med 1999; 189: 1121-8.

[17] Munz C, Steinman RM, Fujii S. Dendritic cell maturation by innate lymphocytes: coordinated stimulation of innate and adaptive immunity. J Exp Med 2005; 202: 203-7.

[18] Ludewig B, Odermatt B, Ochsenbein AF, Zinkernagel RM, Hengartner $\mathrm{H}$. Role of dendritic cells in the induction and maintenance of autoimmune diseases. Immunol Rev 1999; 169: 45-54.

[19] Aloisi F, Pujol-Borrell R. Lymphoid neogenesis in chronic inflammatory diseases. Nat Rev Immunol 2006; 6: 205-17.

[20] Sakaguchi S, Yamaguchi T, Nomura T, Ono M. Regulatory T cells and immune tolerance. Cell 2008; 133: 775-87.
[21] Tang Q, Bluestone JA. The Foxp3+ regulatory T cell: a jack of all trades, master of regulation. Nat Immunol 2008; 9: 239-44.

[22] Steinman RM, Banchereau J. Taking dendritic cells into medicine. Nature 2007; 449: 419-26.

[23] Davidson A, Diamond B. Autoimmune diseases. N Engl J Med 2001; 345: 340-50.

[24] Drakesmith H, Chain B, Beverley P. How can dendritic cells cause autoimmune disease? Immunol Today 2000; 21: 214-7.

[25] Marrack P, Kappler J, Kotzin BL. Autoimmune disease: why and where it occurs. Nat Med 2001; 7: 899-905.

[26] Turley SJ. Dendritic cells: inciting and inhibiting autoimmunity. Curr Opin Immunol 2002; 14: 765-70.

[27] Bayry J, Thirion M, Delignat S, et al. Dendritic cells and autoimmunity. Autoimmun Rev 2004; 3: 183-7.

[28] Lebre MC, Tak PP. Dendritic cells in rheumatoid arthritis: Which subset should be used as a tool to induce tolerance? Hum Immunol 2009.

[29] Ludewig B, Odermatt B, Landmann S, Hengartner H, Zinkernagel RM. Dendritic cells induce autoimmune diabetes and maintain disease via de novo formation of local lymphoid tissue. J Exp Med 1998; 188: 1493-501.

[30] Boyman O, Conrad C, Tonel G, Gilliet M, Nestle FO. The pathogenic role of tissue-resident immune cells in psoriasis. Trends Immunol 2007; 28: 51-7.

[31] Andre S, Tough DF, Lacroix-Desmazes S, Kaveri SV, Bayry J. Surveillance of antigen-presenting cells by CD4+CD25+ regulatory $\mathrm{T}$ cells in autoimmunity. immunopathogenesis and therapeutic implications. Am J Pathol 2009; 174: 1575-87.

[32] Chen M, Wang YH, Wang Y, et al. Dendritic cell apoptosis in the maintenance of immune tolerance. Science 2006; 311: 1160-4.

[33] Ohnmacht C, Pullner A, King SB, et al. Constitutive ablation of dendritic cells breaks self-tolerance of CD4 T cells and results in spontaneous fatal autoimmunity. J Exp Med 2009; 206: 549-59.

[34] Lleo A, Selmi C, Invernizzi P, Podda M, Gershwin ME. The consequences of apoptosis in autoimmunity. J Autoimmun 2008; 31: 257-62.

[35] Fischer M, Ehlers M. Toll-like receptors in autoimmunity. Ann N Y Acad Sci 2008; 1143: 21-34.

[36] Hurst J, von Landenberg P. Toll-like receptors and autoimmunity. Autoimmun Rev 2008; 7: 204-8.

[37] Fallarino F, Grohmann U, Hwang KW, et al. Modulation of tryptophan catabolism by regulatory T cells. Nat Immunol 2003; 4: 120612.

[38] Houot R, Perrot I, Garcia E, Durand I, Lebecque S. Human $\mathrm{CD} 4+\mathrm{CD} 25$ high regulatory $\mathrm{T}$ cells modulate myeloid but not plasmacytoid dendritic cells activation. J Immunol 2006; 176: 5293-8.

[39] Bayry J, Triebel F, Kaveri SV, Tough DF. Human dendritic cells acquire a semimature phenotype and lymph node homing potential through interaction with $\mathrm{CD} 4+\mathrm{CD} 25+$ regulatory $\mathrm{T}$ cells. J Immunol 2007; 178: 4184-93.

[40] Wing K, Onishi Y, Prieto-Martin P, et al. CTLA-4 control over Foxp3+ regulatory T cell function. Science 2008; 322: 271-5.

[41] Valencia X, Stephens G, Goldbach-Mansky R, Wilson M, Shevach EM, Lipsky PE. TNF downmodulates the function of human CD4+CD25hi T-regulatory cells. Blood 2006; 108: 253-61.

[42] Bettelli E, Korn T, Oukka M, Kuchroo VK. Induction and effector functions of T(H)17 cells. Nature 2008; 453: 1051-7.

[43] Nestle FO, Conrad C, Tun-Kyi A, et al. Plasmacytoid predendritic cells initiate psoriasis through interferon-alpha production. J Exp Med 2005; 202: 135-43.

[44] Tisch R, Wang B. Role of plasmacytoid dendritic cells in type 1 diabetes: friend or foe? Diabetes 2009; 58: 12-3.

[45] de Padilla CM, Reed AM. Dendritic cells and the immunopathogenesis of idiopathic inflammatory myopathies. Curr Opin Rheumatol 2008; 20: 669-74.

[46] Gottenberg JE, Cagnard N, Lucchesi C, et al. Activation of IFN pathways and plasmacytoid dendritic cell recruitment in target organs of primary Sjogren's syndrome. Proc Natl Acad Sci USA 2006; 103: 2770-5.

[47] Catani L, Fagioli ME, Tazzari PL, et al. Dendritic cells of immune thrombocytopenic purpura (ITP) show increased capacity to present apoptotic platelets to T lymphocytes. Exp Hematol 2006; 34 : 879-87.

[48] Sakaguchi N, Takahashi T, Hata H, et al. Altered thymic T-cell selection due to a mutation of the ZAP-70 gene causes autoimmune arthritis in mice. Nature 2003; 426: 454-60. 
[49] Lutzky V, Hannawi S, Thomas R. Cells of the synovium in rheumatoid arthritis. Dendritic cells. Arthritis Res Ther 2007; 9: 219.

[50] Cavanagh LL, Boyce A, Smith L, et al. Rheumatoid arthritis synovium contains plasmacytoid dendritic cells. Arthritis Res Ther 2005; 7: R230-40.

[51] Banchereau J, Pascual V, Palucka AK. Autoimmunity through cytokine-induced dendritic cell activation. Immunity 2004; 20: 539-50.

[52] Marshak-Rothstein A. Toll-like receptors in systemic autoimmune disease. Nat Rev Immunol 2006; 6: 823-35.

[53] Blanco P, Palucka AK, Gill M, Pascual V, Banchereau J. Induction of dendritic cell differentiation by IFN-alpha in systemic lupus erythematosus. Science 2001; 294: 1540-3.

[54] Ronnblom L, Pascual V. The innate immune system in SLE: type I interferons and dendritic cells. Lupus 2008; 17: 394-9.

[55] Ding D, Mehta H, McCune WJ, Kaplan MJ. Aberrant phenotype and function of myeloid dendritic cells in systemic lupus erythematosus. J Immunol 2006; 177: 5878-89.

[56] Jin O, Kavikondala S, Sun L, et al. Systemic lupus erythematosus patients have increased number of circulating plasmacytoid den- dritic cells, but decreased myeloid dendritic cells with deficient CD83 expression. Lupus 2008; 17: 654-62.

[57] Crispin JC, Alcocer-Varela J. The role myeloid dendritic cells play in the pathogenesis of systemic lupus erythematosus. Autoimmun Rev 2007; 6: 450-6.

[58] Korn T. Pathophysiology of multiple sclerosis. J Neurol 2008; 255 (Suppl 6): 2-6.

[59] Serafini B, Rosicarelli B, Magliozzi R, et al. Dendritic cells in multiple sclerosis lesions: maturation stage, myelin uptake, and interaction with proliferating $\mathrm{T}$ cells. J Neuropathol Exp Neurol 2006; 65: 124-41.

[60] Miller SD, McMahon EJ, Schreiner B, Bailey SL. Antigen presentation in the CNS by myeloid dendritic cells drives progression of relapsing experimental autoimmune encephalomyelitis. Ann NY Acad Sci 2007; 1103: 179-91.

[61] Wu GF, Laufer TM. The role of dendritic cells in multiple sclerosis. Curr Neurol Neurosci Rep 2007; 7: 245-52.

[62] Zozulya AL, Ortler S, Lee J, et al. Intracerebral dendritic cells critically modulate encephalitogenic versus regulatory immune responses in the CNS. J Neurosci 2009; 29: 140-52.

(C) Maddur et al.; Licensee Bentham Open .

This is an open access article licensed under the terms of the Creative Commons Attribution Non-Commercial License (http://creativecommons.org/licenses/by-nc/3.0/) which permits unrestricted, non-commercial use, distribution and reproduction in any medium, provided the work is properly cited. 